This item was submitted to Loughborough's Research Repository by the author.

Items in Figshare are protected by copyright, with all rights reserved, unless otherwise indicated.

\title{
Disclosure of type 1 diabetes at work among Finnish workers
}

PLEASE CITE THE PUBLISHED VERSION

http://dx.doi.org/10.1111/dme.13134

\section{PUBLISHER}

(C) Diabetes UK. Published by Wiley

\section{VERSION}

AM (Accepted Manuscript)

\section{PUBLISHER STATEMENT}

This work is made available according to the conditions of the Creative Commons Attribution-NonCommercialNoDerivatives 4.0 International (CC BY-NC-ND 4.0) licence. Full details of this licence are available at: https://creativecommons.org/licenses/by-nc-nd/4.0/

\section{LICENCE}

CC BY-NC-ND 4.0

\section{REPOSITORY RECORD}

Hakkarainen, P., L. Moilanen, V. Hanninen, K. Rasanen, and Fehmidah Munir. 2019. “Disclosure of Type 1 Diabetes at Work Among Finnish Workers". figshare. https://hdl.handle.net/2134/21853. 


\section{Disclosure of Type 1 diabetes at work among Finnish workers}

Running title: Type 1 diabetes and disclosure at work

Accepted Version 2016

To be published in Diabetic Medicine

P. Hakkarainen ${ }^{1}$, L. Moilanen ${ }^{2}$, V. Hänninen ${ }^{3}$, K. Räsänen ${ }^{1}$, F. Munir ${ }^{4}$

${ }^{1}$ School of Medicine, Institute of Public Health and Clinical Nutrition, University of Eastern Finland, Kuopio, Finland

${ }^{2}$ Department of Medicine, Kuopio University Hospital, Kuopio, Finland

${ }^{3}$ Department of Social Sciences, University of Eastern Finland, Kuopio, Finland

${ }^{4}$ School of Sport, Exercise, and Health Sciences, Loughborough University, UK

Correspondence to: Pirjo Hakkarainen

Email: pirjoirene.hakkarainen@uef.fi 


\section{What's new?}

- We examined disclosure of Type 1 diabetes to colleagues, line managers and occupational health personnel in a representative national sample.

- Psychosocial factors had the biggest role in workplace disclosure. Social support and psychosocial work ability were associated with disclosure to colleagues, line managers and occupational health personnel. Quality of relationships at work was associated with disclosure to colleagues and to the line manager. Furthermore, opportunity to self-manage diabetes at work was associated with disclosure to colleagues.

- Only half of respondents disclosed their Type 1 diabetes at work and further research is required to examine the reasons for not disclosing Type 1 diabetes. 


\begin{abstract}
Aims To determine which self-management factors and psychosocial work factors were associated with disclosing diabetes to colleagues, line managers and occupational health personnel among workers with Type 1 diabetes.
\end{abstract}

Methods A total of 767 working-aged respondents with Type 1 diabetes completed a Finnish cross-sectional survey named 'People with Type 1 Diabetes in Worklife'. Factor analysis was carried out, followed by logistic regressions to estimate the associations between selfmanagement factors, psychosocial work factors and the likelihood of disclosure separately to colleagues, line managers, and occupational health personnel. The models were adjusted for sociodemographic, diabetes-related and work-related variables.

Results A total of $52 \%$ of the respondents had disclosed their diabetes to their colleagues, $45 \%$ to occupational health personnel, and $28 \%$ to their line manager. Receiving social support and having good psychosocial work ability were significantly associated with disclosure to colleagues, line managers and occupational health personnel. Relations at work were associated with disclosure to colleagues and the line manager. Furthermore, opportunity to self-manage diabetes at work was associated with disclosure to colleagues.

Conclusions Line managers and colleagues have a remarkable role to play in providing workplace support to workers with Type 1 diabetes. Disclosure of Type 1 diabetes should be encouraged as line managers can provide workers with the right support, implement work adaptations and facilitate job retention. As only half of respondents disclosed their Type 1 diabetes at work, further research is required into the reasons for and consequences of not disclosing a diagnosis. 


\section{Introduction}

It is estimated that $~ 95 \%$ of diabetes management is self-management [1]. As workers spend $60 \%$ of their waking hours at work [2], self-management of Type 1 diabetes at work is inevitable.

Self-management of Type 1 diabetes can be challenging at work [3]. In order for workers to selfmanage their diabetes effectively, support may be required from the workplace [4-6]. Studies show that employers do provide support and work adjustments to those who need to manage their chronic health condition at work $[7,8]$. In such cases, workers have disclosed their health condition to their employer (i.e. line manager) or to their colleagues $[7,9,10]$. Compared with other chronic conditions, people with diabetes are less likely to disclose their condition at work [9]. In people with diabetes, workplace disclosure is associated with self-management behaviours at work $[6,11,12]$.

Despite its importance, knowledge of Type 1 diabetes disclosure at work is limited. We examined which self-management and psychosocial work factors were associated with disclosure at work among workers with Type 1 diabetes. In addition, we estimated how those factors were associated with disclosure to colleagues, line manager and occupational health staff.

\section{Materials and methods}

For the present study we tracked a sample of workers diagnosed with Type 1 diabetes. The survey, named 'People with Type 1 Diabetes in Worklife', was conducted by the University of Eastern Finland and the Kuopio University Hospital in 2010-2012. A questionnaire was mailed to a randomly selected sample of 2500 working aged (18-65 years) Finns with Type 1 diabetes. The 
sample was drawn from The Medication Reimbursement Register of the Social Insurance Institution of Finland and covered 6\% of the Finnish population with Type 1 diabetes.

Altogether 2464 people received the questionnaire (four were deceased and 32 were unreachable), and 1214 returned the form. The response rate was $49.3 \%$. We excluded from analysis 201 questionnaires that were filled in incompletely; thus, the final sample of completed questionnaires included 1013 respondents with Type 1 diabetes.

We studied only working Finns with Type 1 diabetes. Those who were retired, unemployed, students and homemakers who had not been working in the last 12 months were excluded. This left a final sample of 767 respondents for analysis (Table 1 ).

The Research Ethics Committee of the Northern Savo Hospital District reviewed and approved the research protocol (18//2010).

\section{Measurements}

The questionnaire contained the following themes: socio-demographics, diabetes background, diabetes and work, health and disclosure of diabetes. The questionnaire included 108 questions and based on previous studies on disclosure at work [9] of those 52 questions were selected for principal axis factor analysis. Seven factors were identified: (1) the opportunity to self-manage diabetes at work (Cronbach's $\alpha=0.841$ ); (2) mental stress attributable to managing diabetes at work (Cronbach's $\alpha=0.832$ ); (3) taking medical time off from work (Cronbach's $\alpha=0.896)$; (4) adhering to self-management at work (Cronbach's $\alpha=0.735)$; (5) social support (Cronbach's $\alpha=$ 0.843 ); (6) relations at work (Cronbach's $\alpha=0.629)$; and (7) psychosocial work ability (Cronbach's 
$\alpha=0.751$ ) (Table S1). The items that fall under each factor are described in the Supporting Information (Appendix S1).

Disclosure of diabetes

The previously used 'Disclosure of illness' measurement [13] was used as a means of measuring disclosure of diabetes. On a scale of 1-5 (not at all to full extent) participants were asked: 'To what extent have you shared the following information about your diabetes with your colleagues: a) type of diabetes and its symptoms; b) ways in which you manage your diabetes at work (e.g. insulin, diet); c) the effect of your diabetes on your work (e.g. on your ability to perform tasks); and d) any time off work needed, related to your diabetes?'. For each item, respondents were asked to report to what extent they had shared information about their diabetes with their colleagues (.881), line manager (.929) and occupational health personnel (.947). For the analyses, we first calculated an overall mean score across the items for disclosure made to colleagues. The single mean score was then dichotomized, $0-1(0=$ not at all; to a small extent; to some extent; and 1 = to a large extent; to a full extent). These steps were repeated for disclosure to line manager and disclosure to occupational health personnel.

\section{Covariates}

Other measures included gender ( $1=$ women; $2=$ men), age (years), education $(1=$ no education or only high school; $5=$ university), length of employment (years), $\mathrm{HbA}_{1 \mathrm{c}}$-level $[1=\leq 60 \mathrm{mmol} / \mathrm{mol}$ $(\leq 7.5 \%) ; 2=61-70 \mathrm{mmol} / \mathrm{mol}(7.6-8.5 \%) ; 3=71-80 \mathrm{mmol} / \mathrm{mol}(8.6-9.5 \%) ; 4=\geq 81 \mathrm{mmol} / \mathrm{mol}$ $(\geq 9.6 \%)$, duration of diabetes (years), comorbidities ( $0=$ no; $1=$ yes), serious hypoglycaemic episodes $(0=$ no; $1=$ yes $)$, number of workers at current work place, working hours, work pattern 
$(0=$ regular, $1=$ irregular $)$ and type of work $(0=$ mentally demanding or equally mentally and physically demanding work; 1 = physically demanding work).

Statistical analysis

Three sets multiple logistic regression analyses were conducted to estimate the associations between the seven factors and the disclosure separately to (a) colleagues, (b) line manager, and (c) occupational health personnel as expressed by odds ratio and $95 \% \mathrm{Cl}$. The models were adjusted for sociodemographic covariates (gender, age, education and length of employment), for diabetesrelated covariates $\left(\mathrm{HbA}_{1 \mathrm{c}}\right.$, duration of diabetes, comorbidities and serious hypoglycaemic episodes), and for work-related covariates (number of workers at current work place, working hours, work pattern and type of work; Table 2). All analyses were carried out in sPss for Windows, Rel. 21.0.0.0, 2012 (SPSS Inc., Chicago, IL, USA). Missing data were excluded from the analysis.

\section{Results}

The characteristics of the 767 participants are summarized in Table 1. Most (68\%) of the participants had good or moderate $\mathrm{HbA}_{1 \mathrm{c}}$ levels. More than $40 \%$ of the participants had a Type 1 diabetes duration of $>10$ years. A total of $52 \%$ of the participants had disclosed their diabetes to their colleagues, $45 \%$ to occupational health personnel and $28 \%$ to their line manager.

In the logistic regression analysis the sociodemographic covariates older age and longer employment were associated with disclosure of Type 1 diabetes to the line manager (Table 2). Workers with longer employment were also more likely to disclose the condition to their colleagues. In addition, older workers disclosed their diabetes to occupational health personnel. 
Of the diabetes-related covariates, higher $\mathrm{HbA}_{1 c}$ level, longer duration of diabetes and serious hypoglycaemic episodes were more likely to be associated with disclosure to the line manager. In the case of serious hypoglycaemic episodes, workers also disclosed their diabetes to their colleagues.

Those with irregular working times were more likely to disclose their condition to their line manager. Workers were more likely to disclose their condition to occupational health personnel if they had physically demanding work and worked for a larger organization.

After adjusting for covariates, the final models showed that receiving social support and having good psychosocial work ability were significantly associated with disclosure to colleagues, line manager and occupational health personnel. Good relations at work were associated with disclosure to colleagues and the line manager. Furthermore, the opportunity to self-manage diabetes at work was associated with disclosure to colleagues.

\section{Discussion}

The present study showed that about half of the participants had disclosed their diabetes to their colleagues and occupational health personnel, and only $28 \%$ to their line manager. Different factors were associated with disclosure to colleagues, line manager and occupational health personnel.

Psychosocial factors had the biggest role in disclosure at work. Workers who had disclosed their condition to colleagues, line manager and occupational health were more likely to report receiving social support from these groups of people and were also more likely to report good psychosocial 
work ability. These results are consistent with other studies that found social support to be important for good self-management of Type 1 diabetes and other chronic conditions at work $[6,14,15]$. In addition, good relations between colleagues and line managers may also encourage disclosure.

Serious hypoglycaemic episodes were associated with disclosure to colleagues and line managers. Higher $\mathrm{HbA}_{1 \mathrm{c}}$ level, and longer duration of diabetes were associated with disclosure to line managers only. These results support previous studies reporting that people with Type 1 or Type 2 diabetes choose to disclose depending on how serious their condition is and which selfmanagement activities are required $[14,16]$. In the present study, individuals who had irregular working times, including shift work, were more likely to disclose their diabetes to their line manager. This may emphasize the line manager's role in implementing work adaptations and facilitating job retention among workers with chronic conditions [17].

The opportunity to self-manage diabetes at work was associated with disclosure to colleagues only. This finding is not surprising as Type 1 diabetes is mainly a self-managed condition where individuals are required to carry out multiple daily self-care activities whilst at work $[4,14,18]$. It may be difficult for a worker with Type 1 diabetes to hide certain self-management activities from their colleagues.

Older workers, those with physically demanding work and those working in larger organizations were more likely to disclose their condition to occupational health personnel. This was to be expected, as these workers have more need for support, and availability of occupational health care is better in large organizations [19]. 
A key strength of the present study is that it included a large representative national sample of 767 working respondents with Type 1 diabetes. The sample represented workers from a wide range of organizations and types of work. The study was cross-sectional, however, and the measurements used were self-reported.

Further longitudinal research should focus on disclosure rates, reasons for choosing not to disclose or deliberately concealing Type 1 diabetes, and the impact of working relationships on disclosure.

Funding sources

This study was supported by The Finnish Work Environment Fund, The Social Insurance Institution of Finland, The Foundation of Kyllikki and Uolevi Lehikoinen and The Finnish Diabetes Association.

Completing interests

None declared.

Acknowledgements

The authors acknowledge all those who participated in this study by filling out and returning the questionnaire. 


\section{References}

1. Diabetes UK. Key statistics on diabetes. A report from Diabetes UK, 2009.

2. Dugdill L, Coffey M. Developing physically active workplace. In: Dugdill L, Crone D, Murphy R, eds. Physical activity and health promotion: Evidence-based approaches to practice. Chichester: Wiley-Blackwell, 2009.

3. Balfe M, Brugha R, Smith D, Sreenan S, Doyle F, Conroy R. Why do young adults with Type 1 diabetes find it difficult to manage diabetes in the workplace? Health Place 2014; 26: 180187.

4. Weijman I, Ros WJ, Rutten GE, Schaufeli WB, Schabracq MJ, Winnubst JA. The role of workrelated and personal factors in diabetes self-management. Patient Educ Couns 2005; 59: 87-96.

5. Detaille SI, Haafkens JA, Hoekstra JB, van Dijk FJ. What employees with diabetes mellitus need to cope at work: views of employees and health professionals. Patient Educ Couns 2006; 64: 183-190.

6. Sato M, Yamazaki Y. Work-related factors associated with self-care and psychological health among people with type 2 diabetes in Japan. Nurs Health Sci 2012; 14: 520-527.

7. Varekamp I, van Dijk FJ. Workplace problems and solutions for employees with chronic diseases. Occup Med (Lond) 2010; 60: 287-293.

8. Boot CR, van den Heuvel SG, Bultmann U, de Boer AG, Koppes LL, van der Beek AJ. Work adjustments in a representative sample of employees with a chronic disease in the Netherlands. J Occup Rehabil 2013; 23: 200-208. 
9. Munir F, Leka S, Griffiths A. Dealing with self-management of chronic illness at work: predictors for self-disclosure. Soc Sci Med 2005; 60: 1397-1407.

10. Brohan E, Henderson C, Wheat K, Malcolm E, Clement S, Barley EA, et al. Systematic review of beliefs, behaviours and influencing factors associated with disclosure of a mental health problem in the workplace. BMC Psychiatry 2012; 12: 11.

11. Bose J. Promoting successful diabetes management in the workplace. International Journal of Workplace Health Management 2013; 6: 205-226.

12. Patel N, Eborall H, Khunti K, Davies MJ, Stone MA. Disclosure of type 1 diabetes status: a qualitative study in a mixed South Asian population in central England. Diversity in Health \& Care 2011; 8: 217-223.

13. Munir F, Yarker J, Haslam C, Long H, Leka S, Griffiths A, Cox S. Work factors related to psychological and health-related distress among employees with chronic illnesses. J Occup Rehabil 2007; 17: 259-77.

14. Ruston A, Smith A, Fernando B. Diabetes in the workplace - diabetic's perceptions and experiences of managing their disease at work: a qualitative study. BMC Public Health 2013; 13: 386.

15. Vassilev I, Rogers A, Kennedy A, Koetsenruijter J. The influence of social networks on selfmanagement support: a metasynthesis. BMC Public Health 2014; 14: 719.

16. Kohinor MJ, Stronks K, Haafkens JA. Factors affecting the disclosure of diabetes by ethnic minority patients: a qualitative study among Surinamese in the Netherlands. BMC Public Health 2011; 11: 399. 
17. Haafkens JA, Kopnina H, Meerman MG, van Dijk FJ. Facilitating job retention for chronically ill employees: perspectives of line managers and human resource managers. BMC Health Serv Res 2011; 11: 104.

18. National Clinical Guideline Centre (UK). Type 1 diabetes in adults, 2015. Available at: https://www.nice.org.uk/guidance/ng17. Last accessed 10 November 2015.

19. Kauppinen T, Mattila-Holappa P, Perkiö-Mäkelä M, Saalo A, Toikkanen J, Tuomivaara S. et al., eds. Työ ja terveys Suomessa 2012 [Work and Health in Finland 2012]. Helsinki: Finnish Institute of Occupational Health, 2013. [In Finnish, summary in English]. Available at http://www.ttl.fi/fi/verkkokirjat/tyo ja terveys suomessa/Documents/Tyo ja Terveys 2012.pdf. Last accessed 28 October 2015.

Supporting Information

Additional Supporting Information may be found in the online version of this article:

Appendix S1. Factor Analysis and supplementary references.

Table S1. Factor structure of disclosure using a principal axis factor analysis and Varimax rotation. 
Table 1. Characteristics of the participants

\begin{tabular}{|c|c|}
\hline Gender $(n=763)$ & \\
\hline Women & $337(44.2)$ \\
\hline Men & $426(55.8)$ \\
\hline Mean \pm SD age, years $(n=760)$ & $36.2 \pm 12,4$ \\
\hline Education $(n=767)$ & \\
\hline No education or only high school & $151(19.7)$ \\
\hline Vocational course & $31(4.0)$ \\
\hline Vocational school & $264(34.4)$ \\
\hline Technical or vocational college, or university of applied & $217(28.3)$ \\
\hline sciences & \\
\hline University & $104(13.6)$ \\
\hline Last $\mathrm{HbA}_{1 c}$ level* $(n=757)$ & \\
\hline$\leq 60 \mathrm{mmol} / \mathrm{mol}(\leq 7.5 \%)$ & $255(33.7)$ \\
\hline $61-70 \mathrm{mmol} / \mathrm{mol}(7.6-8.5 \%)$ & $261(34.5)$ \\
\hline $71-80 \mathrm{mmol} / \mathrm{mol}$ (8.6-9.5\%) & $176(23.2)$ \\
\hline$\geq 81 \mathrm{mmol} / \mathrm{mol}(\geq 9.6 \%)$ & $65(8.6)$ \\
\hline Duration of diabetes $(n=764)$ & \\
\hline $0-5$ years & $186(24.3)$ \\
\hline
\end{tabular}




\begin{tabular}{lc}
\hline $6-10$ years & $249(32.6)$ \\
11-15 years & $291(38.1)$ \\
$\geq 16$ years & $38(5.0)$ \\
Number of workers at current work place $(n=714)$ & \\
1 & $38(5.3)$ \\
2-9 & $184(25.8)$ \\
10-49 & $244(34.2)$ \\
50-249 & $143(20.0)$ \\
To colleagues $(n=684)$ & $105(14.7)$ \\
Mean \pm SD length of employment, years $(n=727)$ & $9.1 \pm 9.9$ \\
\hline
\end{tabular}

Data are $n$ (\%) except where indicated. Missing data were excluded.

*Self-reported. ${ }^{* *}$ Disclosure to Occupational health personnel has been reported only for those who stated their organization had occupational health services. 
Table 2. Adjusted logistic regression model with disclosure, as dependent variable

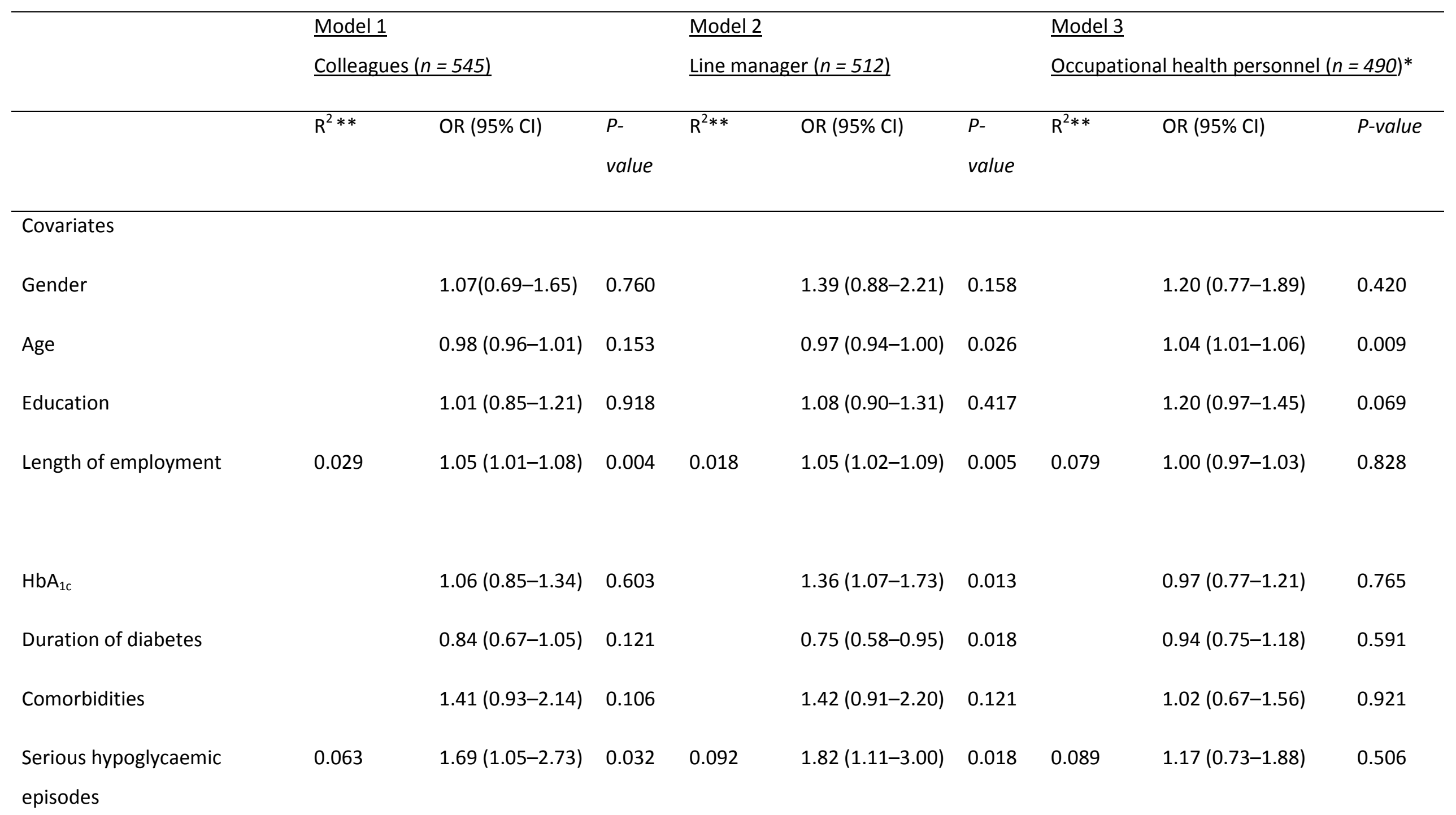


Number of workers at current

$0.92(0.76-1.12) \quad 0.392$

work place

Working hours

Work pattern

Type of work

0.071

$1.01(0.65-1.58) \quad 0.956$

0.116

Factors

Opportunity to self-manage

$1.27(1.04-1.56) \quad 0.018$

diabetes at work

Mental stress due to

managing diabetes at work

Taking medical time from

work

Adhering to self-management

at work

Social support

Relations at work

$0.85(0.70-1.04) \quad 0.123$

$1.06(0.87-1.28) \quad 0.582$

$1.16(0.94-1.44) \quad 0.168$

$2.35(1.87-2.94) \quad 0.000$

$1.23(1.02-1.50) \quad 0.034$
$0.85(0.69-1.04) \quad 0.120$

1.23(1.01-1.49)

0.045

$1.01(0.99-1.03) \quad 0.469$

$1.01(1.00-1.03)$

0.148

$0.57(0.36-0.91) \quad 0.018$

$1.10(0.70-1.72)$

0.692

$0.81(0.51-1.29) \quad 0.377 \quad 0.117$

$1.63(1.02-2.61)$

0.040

$0.82(0.66-1.02) \quad 0.077$

$0.89(0.72-1.10)$

0.295

$1.23(0.99-1.51) \quad 0.061$

$1.15(0.93-1.41)$

0.190

$1.09(0.86-1.37) \quad 0.483$

$1.14(0.91-1.42)$

0.258

$2.17(1.75-2.70) \quad 0.000$

1.49(1.22-1.83)

0.000
$1.40(1.14-1.71) \quad 0.001$ 


\section{OR, odds ratio.}

Missing data were excluded. The models were adjusted for sociodemographic covariates (gender, age, education, and length of employment), for diabetesrelated covariates (HbA1c, duration of diabetes, comorbidities, and serious hypoglycaemic episodes), and for work-related covariates (number of workers at current work place, working hours, work pattern, and type of work).

*Disclosure to Occupational health personnel has been reported only for those who stated their organization had Occupational health services.

${ }^{* *}$ Cumulative Nagelkerke coefficient of determination 